\title{
Estudo das sequelas neuroanatômicas associadas à Síndrome Pós-COVID-19
}

\author{
Study of neuroanatomical sequelae associated with Post-COVID-19 Syndrome
}

Estudio de las secuelas neuroanatómicas asociadas al Síndrome Post-COVID-19

Marina Guimarães Bragatto', Beatriz Melo de Almeida1', Graziela Cesar de Sousa1, Graziele Aparecida Silva $^{1 *}$, Lucas de Souza Gontijo Pessoa ${ }^{1}$, Lucas Klier Silva ${ }^{1}$, Luiza Bitarães Amorim¹, Stael Fernandes Bar ${ }^{1}$, Viviane Teixeira de Sousa'.

\section{RESUMO}

Objetivo: Abordar a fisiopatologia da infecção pelos SARS-CoV-2 e descrever as repercussões neuroanatômicas desencadeadas pela Síndrome Pós-COVID. Revisão bibliográfica: A COVID-19 é uma af ecção respiratória viral aguda. O SARS-CoV-2 é um $\beta$-coronavírus com material genético do tipo RNA com a superfície incrustada de proteínas spike (S) que possibilitam a entrada do patógeno na célula. As manifestações clínicas estão relacionadas à resposta imune do hospedeiro e se caracterizam por acometimentos em diversos órgãos e sistemas. As repercussões neurológicas podem ser não específicas, moderadas e severas. Denomina-se como Síndrome pós-COVID 19 o conjunto de manifestações clínicas que persiste por mais de duas ou três semanas após o início da sintomatologia. Dentre os acometimentos associados, as sequelas neuroanatômicas destacam-se como injúrias capazes de ocasionar morbimortalidade significativa. Por tratar-se de quadro incipiente, não há ainda tratamento padrão instituído para manejo destas sequelas. Considerações finais: A Síndrome Pós-COVID 19 está associada a sequelas importantes, inclusive no Sistema Nervoso Central. Foram descritas diferentes manifestações neurológicas como encefalopatia, acidente vascular cerebral, anosmia, ageusia, tontura, cefaleia, Síndrome de Guillain Barré, dentre outras. Faz-se necessária a condução de mais estudos para que o manejo destes pacientes seja suportado pelas melhores evidências a fim de minimizar as morbidades a longo prazo.

Palavras-chave: COVID-19, SARS-CoV-2, Neuroanatomia, Doenças do sistema nervoso.

\section{ABSTRACT}

Objective: To address the pathophysiology of SARS-CoV-2 infection and describe the neuroanatomical repercussions triggered by Post-COVID Syndrome. Bibliographic review: COVID-19 is an acute viral respiratory disease. SARS-CoV-2 is a $\beta$-coronavirus with RNA-like genetic material with the surface encrusted with spike (S) proteins that allow the pathogen to enter the cell. Clinical manifestations are related to the host's immune response and are characterized by involvement in various organs and systems. Neurological repercussions can be non-specific, moderate and severe. Post-COVID syndrome 19 is the set of clinical manifestations that persist for more than two or three weeks after the onset of symptoms. Among the associated affections, neuroanatomical sequelae stand out as injuries capable of causing significant morbidity and mortality. As this is an incipient condition, there is still no standard treatment instituted to manage these sequelae. Final considerations: Post-COVID Syndrome 19 is associated with important sequelae, including in the Central Nervous System. Different neurological manif estations were described, such as encephalopathy, stroke, anosmia, ageusia, dizziness, headache, Guillain-Barré syndrome, among others. It is necessary to conduct more studies so that the management of these patients is supported by the best evidence in order to minimize long-term morbidities.

Key words: COVID-19, SARS-CoV-2, Neuroanatomy, Nervous system diseases.

\footnotetext{
${ }^{1}$ Pontifícia Universidade Católica de Minas Gerais (PUC-MINAS), Betim - MG.

*E-mail: grazzieleapsilva@gmail.com
} 


\section{RESUMEN}

Objetivo: Abordar la fisiopatología de la infección por SARS-CoV-2 y describir las repercusiones neuroanatómicas desencadenadas por el Síndrome Post-COVID. Revisión bibliografica: COVID-19 es una enfermedad respiratoria viral aguda. EI SARS-CoV-2 es un $\beta$-coronavirus con material genético similar al ARN con la superficie incrustada con proteínas de pico (S) que permiten que el patógeno ingrese a la célula. Las manifestaciones clínicas están relacionadas con la respuesta inmune del huésped y se caracterizan por la participación de varios órganos y sistemas. Las repercusiones neurológicas pueden ser inespecíficas, moderadas y graves. El síndrome post-COVID 19 es el conjunto de manifestaciones clínicas que persisten durante más de dos o tres semanas después del inicio de los síntomas. Entre las afecciones asociadas, destacan las secuelas neuroanatómicas como lesiones capaces de provocar una importante morbimortalidad. Como se trata de una af ección incipiente, aún no existe un tratamiento estándar instituido para manejar estas secuelas. Consideraciones finales: El Síndrome Post-COVID 19 se asocia con importantes secuelas, incluso en el Sistema Nervioso Central. Se describieron diferentes manifestaciones neurológicas, como encefalopatía, ictus, anosmia, ageusia, mareos, cefalea, síndrome de Guillain-Barré, entre otras. Es necesario realizar más estudios para que el manejo de estos pacientes esté respaldado por la mejor evidencia con el fin de minimizar las morbilidades a largo plazo.

Palabras clave: COVID-19, SARS-CoV-2, Neuroanatomía, Enfermedades del sistema nervioso.

\section{INTRODUÇÃO}

Desde os primeiros relatos da infecção pelo novo coronavírus 2 da Síndrome Respiratória Aguda Grave (SARS-CoV-2) ocorridos em 2019, em Wuhan, cidade da China, procura-se entender a complexidade da doença responsável por causar quase 4 milhões de mortes no mundo até junho de 2021. A doença do Coronavírus 2019 (COVID-19) foi definida como pandemia em 2020 e com o avançar dos casos no mundo, reconheceu-se que a maioria dos casos tem prognóstico favorável, ainda que indivíduos idosos e com condições crônicas subjacentes estejam mais vulneráveis a apresentarem quadros de maior gravidade (COSTA A e PINTO AS, 2020).

Observa-se que sintomas como fadiga, tosse, febre, anosmia e ageusia ocorrem com frequência considerável na fase inicial da infecção. No entanto, algumas manifestações como tosse, anosmia, ageusia, dispneia, fadiga e confusão mental podem se estender por um longo período, sendo esse quadro posterior definido como Síndrome pós-Covid-19. No que tange aos sintomas relacionados ao sistema nervoso, sabese que, sob certas condições, o vírus SARS-CoV-2 é capaz de causar complicações neurológicas que podem desencadear repercussões neuroanatômicas. Nesse contexto, observou-se que a manifestação do SARSCoV-2 é de elevada complexidade devido aos múltiplos com apresentar, principalmente em relação aos desfechos (CAROD-ARTAL FJ, 2020; FERNÁNDEZ-DE-LAS-PEÑAS C, et al., 2021).

Diante desse risco, nota-se a importância do estudo em relação ao tropismo do vírus pelo Sistema Nervoso Central (SNC) e das hipóteses que buscam entender o mecanismo utilizado pelo Sars-CoV-2 para penetrar esse sistema. Faz-se relevante, ainda, citar que as manifestações neurológicas iniciam-se geralmente entre o primeiro e o décimo quarto dia após o começo dos sintomas respiratórios, de forma mais frequente no doente grave ou crítico, sendo os relatos mais comuns de cefaleia, anosmia e ageusia (COSTA A e PINTO AS, 2020). Torna-se pertinente, portanto, a abordagem da síndrome pós-COVID no que tange às alterações neuroanatômicas ocasionadas pela infecção (CAROD-ARTAL FJ, 2020).

Diante do contexto de uma pandemia, é plausível que inúmeros estudos busquem compreender a fisiopatologia da nova doença e o manejo dos casos agudos, sobretudo de pacientes em hospitalização. No entanto, o impacto e a recorrência das sequelas oriundas da COVID-19 reforçam a necessidade de produções científicas que abordem a Síndrome Pós-COVID-19. Nesse sentido, este artigo objetiva expor evidências acerca das sequelas neurológicas que comprometam de alguma maneira o funcionamento fisiológico do SNC ou do Sistema Nervoso Periférico (SNP) no período subsequente à recuperação da infecção por COVID -19. 


\section{REVISÃO BIBLIOGRÁFICA}

\section{O SARS-COV-2: Epidemiologia e Fisiopatologia da Infecção}

A COVID-19 é uma af ecção respiratória causada pelo novo coronavírus 2 da síndrome respiratória aguda grave (SARS-CoV-2) e teve seus primeiros casos relatados em dezembro de 2019 na China. Essa condição clínica cursa, principalmente, com febre, tosse seca e dispneia, muito embora outros sintomas sejam, frequentemente, relatados. Homens e mulheres parecem ser igualmente afetados e a faixa etária de maior prevalência é em torno da quarta década de vida. Além disso, sabe-se que idosos com comorbidades, incluindo doença pulmonar, doença cardíaca, doença renal, diabetes e hipertensão podem cursar com pior prognóstico (GUAN W, et al., 2020).

Até o dia 21 de junho de 2021, a COVID-19 acometeu 17.927.928 pessoas e deixou um registro de 501.825 mortes no Brasil. Devido à rápida disseminação da doença e à alta contaminação, essa inf ecção foi declarada pela Organização Mundial da Saúde (OMS) como uma emergência de saúde pública de interesse internacional e, em março de 2020, o Ministério da Saúde do Brasil reconheceu o estado de pandemia no país (PAINEL CORONAVÍRUS, 2021).

Os coronavírus são vírions pertencentes à família Coronaviridae, assim identificados pelo formato de sua superfície quando vistos ao microscópio. Alguns desses patógenos estão relacionados a af ecções do sistema respiratório de caráter mais letal e são responsáveis por desencadear surtos como a Síndrome Respiratória Aguda Grave, relacionada ao SARS-CoV (vírus da síndrome respiratória aguda grave) e a Síndrome Respiratória do Oriente Médio, provocada pelo MERS-CoV (vírus da síndrome respiratória do Oriente Médio). O SARS-CoV-2 é um betacoronavírus com material genético do tipo RNA e em sua superfície apresenta proteínas chamadas spike (S) que são responsáveis por permitir a ligação ao receptor da célula hospedeira e possibilitar a entrada do vírus nessa célula (HUANG Y, et al., 2020; GUAN W, et al., 2020; MURRAY PR, et al., 2016).

A proteína S, presente na região mais externa do vírus, é um fator determinante para a infecção. Essas proteínas spikes são glicoproteínas transmembrana triméricas de classe I e consistem em um terminal $\mathrm{N}$ extracelular, um domínio transmembrana ancorado na membrana viral e um segmento C-terminal intracelular curto. Um aspecto notável dessas proteínas é que elas mantêm polissacarídeos em suas porções finais na tentativa de passarem despercebidas pelo sistema imunológico do indivíduo infectado (HUANG Y, et al., 2020).

As proteínas $\mathrm{S}$ atuam como precursor inativo no organismo, de forma que, durante a infecção, essas proteínas são ativadas e clivadas em suas subunidades S1 e S2. Essa etapa é indispensável para a fusão da membrana do vírus com a membrana da célula-alvo. A subunidade $\mathrm{S} 1$ apresenta um importante papel no início da infecção viral. Essa subunidade reconhece o receptor da enzima conversora de angiotensina 2 (ECA2) e se liga a esse receptor na superfície da célula hospedeira por meio da interação do domínio de ligação ao receptor na região $\mathrm{N}$. Já a subunidade $\mathrm{S} 2$ apresenta, principalmente, a região repetição de heptapeptídeo (HR) que contém o domínio HR1 e HR2, os quais estão intimamente relacionados à fusão do vírus. Essa subunidade é responsável por viabilizar a fusão da membrana celular do hospedeiro com o vírus, permitindo, assim, a entrada deste na célula-alvo (HUANG Y, et al., 2020; ZHANG H, et al., 2020).

As enzimas conversoras de angiotensina 2 (ECA 2), que correspondem ao receptor do vírus na célula humana, são encontradas, principalmente, na superfície de órgãos como pulmão, intestino, coração e rim, sendo as células epiteliais alveolares do tipo II as que apresentam maior expressão dessa enzima (HUANG Y, 2020; ZHANG H, et al., 2020; WAN Y, et al., 2020).

O estudo de Li MY, et al. (2020), aponta a presença do receptor ECA 2 em 31 tecidos humano. Alguns tecidos demonstraram elevada expressão desse receptor, tais como intestino delgado, testículos, rins, coração, tireoide e tecido adiposo, enquanto outros apresentaram níveis moderados a baixos, como pulmões, cólon, fígado, bexiga, glândula adrenal, sangue, baço, medula óssea, vasos sanguíneos, músculos e cérebro. A partir desse estudo, é possível compreender que a infecção pelo vírus SARS-CoV-2 não está limitada aos tecidos do trato respiratório, bem como pode acometer tecid os nobres como o cérebro. 
Diante da ampla distribuição desse receptor nas células humanas, e, considerando sua presença em tecidos neurais, mostra-se útil a investigação acerca da relação da infecção pelo SARS-CoV-2 e as sequelas neurológicas observadas nos pacientes acometidos por esse vírus (LI MY, et al., 2020; PATEL AB e VERMA A, 2020).

\section{COVID-19: Manifestações clínicas da infecção aguda}

Estudos mostraram que grande parte da sintomatologia da COVID-19 é explicada pela tempestade de citocinas desencadeada pelo vírus, conduzindo a uma Síndrome de Resposta Inflamatória Sistêmica (SIRS). Esta resposta imunológica exacerbada leva à produção de uma grande quantidade de mediadores inflamatórios cujo objetivo primário é o combate à infecção pelo SARS-CoV-2, mas que concomitantemente provoca danos teciduais importantes (ABBOUD H, et al., 2020).

Dentre os sintomas mais comuns, é possível citar aqueles ligados ao sistema respiratório, como tosse seca e fadiga. No entanto, pesquisas revelaram que $40 \%$ dos infectados pelo SARS-CoV-2 desenvolvem sintomas neurológicos, evidenciando a capacidade do vírus de causar repercussões no tecido nervoso. Alguns dos sintomas respiratórios decorrentes da doença podem ser consequências do acometimento do Sistema Nervoso Central, mais precisamente no Centro Respiratório. O vírus pode infectar as células neuronais do tronco encefálico, particularmente do bulbo, desencadeando sintomas respiratórios, como consequência do comprometimento do centro cardiovascular e do centro respiratório (ALOMARI SO, et al., 2020).

Dessa forma, os danos neurológicos podem estar implicados na gênese da insuficiência respiratória aguda característica dos pacientes com COVID-19. Considerando o potencial invasivo do vírus ao sistema nervoso, as manifestações neurológicas da doença podem ser classificadas quanto à sua severidade como não específico, moderado e severo (ALOMARI SO, et al., 2020; JASTI M, et al., 2020).

Entre os sintomas não específicos e sistêmicos podemos citar a cefaléia como o mais frequente, provavelmente desencadeada pela ação da febre associada a componentes da resposta imunológica. Já dentre os acometimentos moderados, os mais relatados pelos pacientes foram ageusia, disfunções olf atórias, incluindo hiposmia ou anosmia, e disfunção visual (ALOMARI SO, et al., 2020).

Acredita-se que a perda de olfato pós infecção seja primeiramente causada pela congestão nasal inicial, que leva a disfunção das terminações das células receptoras olfativas, tornando-as ineficazes na captação de moléculas de odor. O SARS-CoV-2 também parece estar altamente concentrado nas narinas dos pacientes af etados, entrando por meio da lâmina cribiforme e proporcionando inflamação dos nervos olfatórios e dano estrutural aos receptores e, portanto, causando anosmia (ALOMARI SO, et al., 2020).

Alguns estudos mostraram que a língua é um local rico em receptores ACE2, sendo um local potencial de ligação do vírus, causando danos aos receptores do paladar, levando a ageusia. Em grande parte dos casos, a ageusia e a anosmia representam a primeira ou a única manifestação sintomatológica da doença, podendo considerá-las acometimentos relevantes para auxílio diagnóstico, na suspeita de pacientes infectados (VAIRA LA, et al., 2020; JASTI M, et al., 2020).

A desordem mental, o delírio e a disforia podem ser indícios de encefalopatias infecciosas tóxicas, outro acometimento moderado, uma vez que representam manifestações diretas do SARS-CoV-2 no Sistema Nervoso Central. A infiltração viral direta no SNC pode desencadear uma reação neuroinflamatória levando à ativação da micróglia, a qual proporciona processos desmielinizantes, sendo uma das causas principais das encefalopatias. Na ausência de infiltração viral direta, a cascata de citocinas desencadeia uma resposta neuroinflamatória, causando ruptura da barreira hematoencefálica com a transmigração das células imunológicas da periferia para o sistema nervoso central, causando, por sua vez, os desequilíbrios na neurotransmissão. Apesar de raros e severos, alguns casos de encefalopatias podem levar a epilepsia, paralisia e perda de consciência, podendo chegar também ao coma (WU Y, et al., 2020; ABBOUD H, et al., 2020; JASTI M, et al., 2020).

Por fim, entre os sintomas severos foram reportados casos de eventos cerebrovasculares, como por exemplo hemorragias intracerebrais, trombose venosa cerebral e acidentes vasculares cerebrais isquêmicos. Além disso, embora ainda seja incerta a participação desse vírus nessas ocorrências, foram deportados casos 
de doenças neurodegenerativas como Alzheimer, Síndrome de Guillain-Barré e Esclerose Múltipla, sendo necessários estudos futuros para correlacionar tais eventos ao processo fisiopatológico da COVID-19 (ABBOUD H, et al., 2020; WANG F, et al., 2020b).

\section{A Síndrome Pós-covid: repercussões neuroanatômicas}

A Síndrome Pós-COVID-19 recebe diversas nomeações, sendo também conhecida por "COVID-19 pósagudo", "Sintomas COVID-19 persistentes", "Manifestações pós-COVID-19", "Efeitos de longo prazo da COVID-19", "COVID longo". Entende-se que os acometimentos que persistirem por mais de duas ou três semanas após o início da doença, podem ser classificados como pertencentes à Síndrome pós-COVID-19. Grande parte da literatura científica dedica-se à fisiopatologia da doença e ao acometimento agudo. Porém, como o número de sobreviventes é vasto e muitos destes possuem sintomas que perduram por um tempo além do esperado, autores têm considerado a Síndrome pós-COVID-19 como uma segunda pandemia, o que justifica a necessidade de aprofundamento dessa temática (MALTEZOU H, et al., 2021; FERNÁNDEZ-DELAS-PEÑAS C, et al., 2021).

Fernández-de-las-Peñas C, et al. (2021), a partir de uma revisão sistemática e meta-análise, estimaram que mais de $60 \%$ dos sobreviventes da COVID-19 apresentam ao menos um sintoma por mais de 30 dias após o início da doença ou da hospitalização. Fadiga e dispneia despontam como os sintomas mais frequentes da síndrome. Outros acometimentos como cef aléia, anosmia, ageusia, dor torácica ou palpitações tiveram prevalência menor e com alta variação. Lopez-Leon S, et al. (2021) são autores de outra importante meta-análise que ainda está na fase de preprint. Tal estudo revela que fadiga, cefaléia, distúrbios de atenção, queda de cabelo e dispneia foram os sintomas mais prevalentes na síndrome.

A COVID-19 provoca repercussões neuroanatômicas. O SNC e SNP são gravemente af etados pelo SARSCoV-2, ocasionando sequelas neuronais que a longo prazo podem, inclusive, estar relacionadas a doenças crônico-degenerativas. De início, pensou-se que o SARS-CoV-2 teria grande dificuldade em atravessar a barreira hematoencefálica $(\mathrm{BHE})$. Posteriormente, constatou-se que o receptor de ligação à proteína SARSCoV-2 spike (S), ACE2, é bastante expresso em células endoteliais microvasculares do cérebro. A proteína $S$ pode, também, danificar em vários graus a integridade da BHE, além de poder induzir resposta inflamatória das células endoteliais que alteram a função da BHE. Essas descobertas corroboram a ação do vírus na BHE e, portanto, sua entrada no cérebro, favorecendo a ocorrência de microtrombos e encefalite associada à COVID-19 (WANG F, et al., 2020a).

Há relato de paciente com COVID-19 que foi acometido por tosse, febre e alteração no estado mental. Ele foi diagnosticado com encefalopatia necrosante aguda. Uma tomografia computadorizada sem contraste foi realizada neste paciente, o que demonstrou hipoatenuação simétrica dentro do tálamo medial bilateral com angiografia e venograma normais. Já a ressonância magnética revelou lesões características de realce da borda hemorrágica nos tálamos, lobos temporais mediais e regiões subinsulares (POYIADJI N, et al., 2020).

Conforme Maltezou H, et al. (2021), a patogênese da síndrome pós-COVID 19 ainda é amplamente desconhecida. A inflamação prolongada tem um papel fundamental na gênese da maioria das manifestações da síndrome. Isso pode ser exemplificado já que o processo inflamatório associado ao vírus pode levar ao comprometimento do ácido gama-aminobutírico (GABA), possivelmente representando a base da fadiga neuromotora e cognitiva, explicando a apatia e déf icits executivos. Estudos sugerem que o hipocampo parece ser particularmente vulnerável à infecção, o que contribuiria para o déficit de memória pós-infecção. Wostyn P (2021) propôs a hipótese de que a síndrome de fadiga pós-COVID 19 pode resultar de danos aos neurônios sensoriais olf atórios, causando um fluxo reduzido de líquido cefalorraquidiano, por meio da placa cribriforme e levando à congestão do sistema linfático com subsequente acúmulo tóxico dentro do Sistema Nervoso Central. Além disso, a neuroinvasão direta do SARS-CoV-2 pode levar a complicações neuropsiquiátricas persistentes.

Um estudo conduzido por Sher L (2021), corrobora outros autores supracitados. Para ele, como exemplo de manifestações neurológicas de COVID-19 tem-se encefalopatia, acidente vascular cerebral, anosmia, ageusia, tontura, dor de cabeça, Síndrome de Guillain-Barré, Síndrome de Miller Fisher e mialgia do músculo esquelético. Condições epilépticas foram observadas em pacientes com COVID-19, como crises de início 
recente, crises convulsivas, crises mioclônicas, estado de mal epiléptico e estado epiléptico ref ratário de início recente. Os sintomas neurológicos relacionados à doença podem persistir por muito tempo após a doença aguda do SARS-CoV-2, sendo encontrados, portanto, na síndrome pós-COVID-19. Além disso, há uma probabilidade significativa de que os sintomas psiquiátricos, doenças neurológicas, físicas e também os danos inflamatórios no cérebro em indivíduos com síndrome aumentem a ideação e o comportamento suicida. No entanto, pacientes que não tiveram síndrome pós-COVID-19 também podem apresentar risco elevado de suicídio.

\section{Manejo dos Danos Neurológicos}

O tratamento da COVID-19 e de suas manifestações neurológicas ainda é muito discutido, não havendo protocolo sistematizado. Atualmente, o manejo mais recomendado para o tratamento dos sintomas de menor gravidade relacionados a SNC, como febre (visto que o vírus altera o centro termorregulador) e cefaleia é com o uso de paracetamol, em virtude do alívio dos sintomas relatados e da baixa probabilidade de complicação. Além disso, demais antiinflamatórios são, também, uma terapia potencial, especialmente em sintomas mais complicados. Quanto ao bloqueio da atividade viral, e, em última instância, das manifestações do SNC, os inibidores da furina também são um possível tratamento, já que impedem a ligação das proteínas spikes virais em seu sítio de atuação celular. No entanto, há limitações importantes quanto ao seu uso, uma vez que a furina possui importante papel na fisiologia normal do tecido nervoso (FIANI B, et al., 2020).

Inúmeras alterações neurológicas estão associadas à COVID-19. Como se trata de uma doença ainda recente, é inviável estabelecer todas as manifestações possíveis. Atualmente, não há um tratamento global que cesse todas as possíveis lesões. A principal alternativa para o controle da doença ainda são as vacinas, mas, até que o processo de vacinação se dê, os esforços devem estar centrados no controle da insuficiência respiratória, falência de órgãos, estado de hipercoagulação e desregulação imunológica. Não há, pois, um tratamento específico, sendo que as manifestações neurológicas devem ser tratadas de acordo com seu protocolo padrão (IADECOLA C, et al., 2020).

No entanto, como as complicações neurológicas surgem principalmente na doença sistêmica grave, é importante minimizar a hipóxia e proteger o cérebro de citocinas e complicações tromboembólicas, sendo, portanto, objetivos terapêuticos importantes. A imunossupressão com esteróides melhora a mortalidade em pacientes com doença grave, mas não naqueles com formas mais leves. Abordagens diferenciadas para neutralizar a desregulação imunológica, como alvejar citocinas específicas ou vias inflamatórias, também estão sendo testadas. Ademais, ainda não foi estabelecido se essas intervenções reduzem as complicações neurológicas e psiquiátricas de curto e longo prazo (IADECOLA C, et al., 2020).

Por fim, uma vigilância adicional adequada da infecção intracraniana em pacientes com COVID-19 possibilitaria maiores informações acerca de seu prognóstico neurológico. Além disso, imagens de ressonância magnética do crânio, juntamente com procedimentos de punção lombar para coletar líquido cefalorraquidiano, destacariam essa associação neuroinvasiva do patógeno. Para pacientes com infecção intracraniana definitiva, as estratégias de tratamento sugeridas são controlar o edema cerebral, tratar e prevenir convulsões e tratar os sintomas psicóticos. Já para os pacientes que apresentam sintomas associados a danos musculares, o fortalecimento do suporte nutricional é recomendado além do tratamento ativo contra o vírus (FIANI B, et al., 2020).

\section{CONSIDERAÇÕES FINAIS}

A pandemia da COVID-19 incutiu nos profissionais de saúde a inevitabilidade de se buscar a fisiopatologia, a sintomatologia, a profilaxia e demais conhecimentos que embasam sua terapêutica. Embora não haja consenso em muitos aspectos relacionados aos acometimentos do SARS-CoV-2, há, hoje, consonância entre estudiosos de que emerge uma nova pandemia: a Síndrome pós-COVID 19. As repercussões neuroanatômicas revelam o quanto o sistema nervoso é af etado pelo vírus tanto na fase aguda, quanto na COVID-19 crônica. Compreender as manifestações e os acometimentos neuroanatômicos é fator imprescindível para que sejam mitigados os danos neurológicos oriundos da COVID-19. Sendo assim, a 
realização de novos estudos cujo enfoque seja o pós-COVID apresenta grande potencial e colaborapara uma abordagem mais integral do paciente acometido pela infecção e não apenas da doença em si e de suas repercussões imediatas.

\section{REFERÊNCIAS}

1. ABBOUD H, et al. COVID-19 and SARS-Cov-2 Infection: Pathophysiology and Clinical Effects on the Nervous System. World neurosurgery, 2020;140:49-53.

2. ALOMARI SO, et al. COVID-19 and the central nervous system. Clinical Neurology and Neurosurgery, 2020; 198: 106116.

3. CAROD-ARTAL FJ. Neurological complications of coronavirus and COVID-19. Revista de Neurologia, 2020;70:311322.

4. COSTA A, PINTO AS. Manifestações Neurológicas e COVID-19. Acta Medica Portuguesa, 2020;33(12): 787-788.

5. ESCOSTEGUY C, et al. COVID-19: estudo seccional de casos suspeitos internados em um hospital federal do Rio de Janeiro e fatores associados ao óbito hospitalar. Epidemiologia e Serviços de Saúde, 2021;30(1).

6. FERNÁNDEZ-DE-LAS-PEÑAS C, et al. Prevalence of Post-COVID-19 Symptoms in Hospitalized and NonHospitalized COVID-19 Survivors: A Systematic Review and Meta-Analysis. European Journal of Internal Medicine, 2021.

7. FIANI B, et al. A Contemporary Review of Neurological Sequelae of COVID-19. Frontiers in Neurology, 2020:11; 19.

8. GUAN W, et al, Clinical Characteristics of Coronavirus Disease 2019 in China. N Engl J Med, 2020;382: 1708-1720.

9. HUANG Y, et al. Structural and functional properties of SARS-CoV-2 spike protein: potential antivirus drug development for COVID-19. Acta Pharmacol Sin, 2020;41: 1141-1149.

10. IADECOLA C, et al. Effects of COVID-19 on the Nervous System. Cell, 2020;183 (1): 16-27.

11. JASTI M, et al. A review of pathophysiology and neuropsychiatric manifestations of COVID -19. Journal of Neurology, 2020;268(6): 2007-2012.

12. LI MY, et al. Expression of the SARS-CoV-2 cell receptor gene ACE2 in a wide variety of human tissues. Infectious Diseases of Poverty, 2020; 9(1): 45.

13. LOPEZ-LEON S, et al. More than 50 Long-term effects of COVID-19: a systematic review and meta-analysis. medRxiv: the preprint server for health sciences, 2021.

14. MALTEZOU H, et al. Post-COVID Syndrome: An Insight on Its Pathogenesis. Vaccines, $2021 ; 9(5): 497$.

15. MURRAY PR, et al. Coronavírus e Norovírus. Microbiologia Médica. 8 ed. Rio de Janeiro: Elsevier, 2017;888p.

16. PAINEL CORONAVÍRUS, 2021. In: CORONAVIRUS Brasil. Brasília: DataSUS. Disponível em: https://covid.saude.gov.br/. Acesso em:21 jun. 2021.

17. PATEL AB, VERMA A. COVID-19 and Angiotensin-Converting Enzyme Inhibitors and Angiotensin Receptor Blockers What Is the Evidence? Jama, 2020;323(18):1769-1770.

18. POYIADJI N, et al. COVID-19-associated acute hemorrhagic necrotizing encephalopathy: imaging features. Radiology, 2020;296(2): E119-E120.

19. SHER L. Post-COVID syndrome and suicide risk. QJM: An International Journal of Medicine, 2021;114(2):95-98.

20. VAIRA LA, et al. Anosmia and Ageusia:Common Findings in COVID-19 Patients. The Laryngoscope, 2020;130 (7): 1787-1787.

21. WAN Y, et al. Receptor Recognition by the Novel Coronavirus from Wuhan: an Analysis Based on Decade-Long Structural Studies of SARS Coronavirus. J Virol, 2020;94:120-127.

22. WANG F, et al. An Evidence Based Perspective on mRNA-SARS-CoV-2 Vaccine Development. Medical science monitor, 2020a;26: e924700-1-e924700-8.

23. WANG F, et al. Long-Term Respiratory and Neurological Sequelae of COVID-19. Medical science monitor, 2020b; 26: e928996.

24. WOSTYN P. COVID-19 and chronic fatigue syndrome: Is the worst yet to come?. Medical hypotheses, 2021; 146 : 110469.

25. WU Y, et al. Nervous system involvement after infection with COVID-19 and other coronaviruses. Brain, Behavior, and Immunity, 2020;87: 18-22.

26. ZHANG H, et al. Angiotensin-converting enzyme 2 (ACE2) as a SARS-CoV-2 receptor: molecular mechanisms and potential therapeutic target. Intensive Care Med, 2020: 46; 586-590. 